University of Nebraska - Lincoln

DigitalCommons@University of Nebraska - Lincoln

Center for Brain, Biology and Behavior: Papers \&

Publications

Brain, Biology and Behavior, Center for

$10-1-2017$

\title{
Examining the relationship between home literacy environment and neural correlates of phonological processing in beginning readers with and without a familial risk for dyslexia: an fMRI study
}

\author{
Sara J. Powers \\ Boston Children's Hospital \& Harvard Medical School \\ Yingying Wang \\ Boston Children's Hospital \& Harvard Medical School, yingying.wang@unl.edu \\ Sara D. Beach \\ Harvard University \\ Georgios D. Sideridis \\ Boston Children's Hospital \\ Nadine Gaab

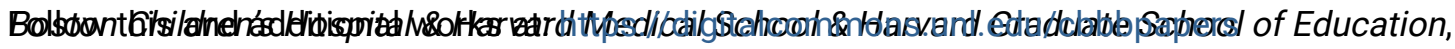 \\ dine.gaab@childrens.harvard.edu \\ Part of the Behavior and Behavior Mechanisms Commons, Nervous System Commons, Other \\ Analytical, Diagnostic and Therapeutic Techniques and Equipment Commons, Other Neuroscience and \\ Neurobiology Commons, Other Psychiatry and Psychology Commons, Rehabilitation and Therapy \\ Commons, and the Sports Sciences Commons
}

Powers, Sara J.; Wang, Yingying; Beach, Sara D.; Sideridis, Georgios D.; and Gaab, Nadine, "Examining the relationship between home literacy environment and neural correlates of phonological processing in beginning readers with and without a familial risk for dyslexia: an fMRI study" (2017). Center for Brain, Biology and Behavior: Papers \& Publications. 52.

https://digitalcommons.unl.edu/cbbbpapers/52

This Article is brought to you for free and open access by the Brain, Biology and Behavior, Center for at DigitalCommons@University of Nebraska - Lincoln. It has been accepted for inclusion in Center for Brain, Biology and Behavior: Papers \& Publications by an authorized administrator of DigitalCommons@University of Nebraska Lincoln. 


\title{
Examining the relationship between home literacy environment and neural correlates of phonological processing in beginning readers with and without a familial risk for dyslexia: an fMRI study
}

\author{
Sara J. Powers ${ }^{1,2, \dagger}$, Yingying Wang ${ }^{1,2, \dagger}$, Sara D. Beach ${ }^{3}$, Georgios D. Sideridis ${ }^{1}$, and Nadine \\ Gaab $^{1,2,4}$ \\ ${ }^{1}$ Division of Developmental Medicine, Department of Medicine, Boston Children's Hospital, \\ Boston, MA, USA \\ ${ }^{2}$ Harvard Medical School, Boston, MA, USA \\ ${ }^{3}$ Speech and Hearing Bioscience and Technology Program, Division of Medical Sciences, \\ Harvard University, Boston, MA, USA \\ ${ }^{4}$ Harvard Graduate School of Education, Cambridge, MA, USA
}

\section{Abstract}

\begin{abstract}
Developmental dyslexia is a language-based learning disability characterized by persistent difficulty in learning to read. While an understanding of genetic contributions is emerging, the ways the environment affects brain functioning in children with developmental dyslexia are poorly understood. A relationship between the home literacy environment (HLE) and neural correlates of reading has been identified in typically developing children, yet it remains unclear whether similar effects are observable in children with a genetic predisposition for dyslexia. Understanding environmental contributions is important given that we do not understand why some genetically atrisk children do not develop dyslexia. Here we investigate for the first time the relationship between HLE and the neural correlates of phonological processing in beginning readers with (FHD+, n=29) and without (FHD-, n=21) a family history of developmental dyslexia. We controlled for socio-economic status to isolate the neurobiological mechanism by which HLE affects reading development. Group differences revealed stronger correlation of HLE with brain activation in the left inferior/middle frontal and right fusiform gyri in FHD- compared to FHD+ children, suggesting greater impact of HLE on manipulation of phonological codes and recruitment of orthographic representations in typically developing children. In contrast, activation in the right precentral gyrus showed a significantly stronger correlation with HLE in FHD+ compared to FHD- children, suggesting emerging compensatory networks in genetically at-risk children. Overall, our results suggest that genetic predisposition for dyslexia alters contributions of HLE to early reading skills before formal reading instruction, which has important implications for educational practice and intervention models.
\end{abstract}

Address for correspondence: Nadine Gaab, Ph.D., Children's Hospital, Boston, Department of Medicine, Division of Developmental Medicine, Laboratories of Cognitive Neuroscience, 1 Autumn Street, Mailbox \# 713, Boston, MA 02115.

†equally contributing authors, co-first authorship 


\section{Keywords}

Dyslexia; fMRI; Home Literacy Environment; Phonological Processing

\section{Introduction}

Early reading is an essential skill that affects the development of literacy and is supported by experiences throughout the childhood years (Adams 1990; Ehri 2005). Most children begin formal reading education in kindergarten, however, by the time children reach this age, many genetic and environmental factors have already begun to shape their future reading ability (Whitehurst and Lonigan 1998). Developmental dyslexia (DD) provides an example of how literacy acquisition can be affected by complex genetic and environmental interactions (Ozernov-Palchik et al. In press). DD is a language-based learning disability that affects 5$17 \%$ of all children (WHO 1992; Lyon et al. 2003). It is characterized by difficulties with speed and accuracy of word/text decoding and poor spelling and comprehension performance (Siegel 2006). Deficits may further include speech perception, the accurate representation and manipulation of speech sounds, problems with language memory, rapid automatized naming, or letter sound knowledge (O’Brien et al. 2012). Genetic contributions to reading ability have been demonstrated (Grigorenko 2004; Galaburda et al. 2006; Kere 2014; Galaburda et al. 1985; Darki et al. 2012; Swanson et al. 2015), and familial risk studies suggest that DD is strongly heritable, occurring in up to $68 \%$ of identical twins (DeFries and Alarcón 1996). However, a concordance rate of less than $100 \%$ indicates contributions of the environment in DD. It is important to examine how these environmental factors may affect children with and without DD, given that some children who are genetically predisposed do not go on to develop dyslexia. Understanding the role that the environment may play in the neurobiological circuits of reading in children with and without family history of dyslexia will provide much-needed insight into how variables other than genetics influence emergent literacy in children.

Several environmental factors have been shown to contribute to development of early reading skills in children, including socioeconomic status (SES), home literacy environment (HLE) and characteristics of home language (Peterson and Pennington 2015; Christopher et al. 2015). SES is a diverse construct that encompasses factors such as education, occupation, material wealth and prestige. In children, SES has been shown to affect several different areas of cognition, including language, executive function, and memory (Brito and Noble 2014; Hackman and Farah 2009; Raizada and Kishiyama 2010). While related to SES, the HLE that a child experiences from infancy throughout the preschool years has been suggested to be a contributor of unique variance to development of early reading skills (Hamilton 2013; Payne et al. 1994). Broadly, HLE characterizes the literacy-related interactions and resources in the home and may vary regardless of SES. While the accepted indicators of HLE are not consistent across studies, factors such as shared reading between parents and preschoolers, exposure to literacy materials, and reading instruction are often included (Payne et al. 1994; Scarborough et al. 1991). These components of the home environment have been shown to account for some of the effects of SES on cognitive development (Bus et al. 1995; Frijters et al. 2000; Hamilton 2013; Payne et al. 1994). 
Indeed, a comprehensive meta-analysis by Bus et al. reported that shared reading accounts for $8 \%$ of unique variance in child language, and emergent literacy, confirming an earlier review by Scarborough and Dobrich that identified an association between joint parent-child book reading and child's reading achievement (Bus et al. 1995; Scarborough and Dobrich 1994). Several studies have also demonstrated the importance of HLE for child reading development when controlling for SES (Payne et al. 1994; Rodriguez and Tamis-LeMonda 2011; Smith and Dixon 1995). Furthermore, early HLE mediates effects of SES on emergent literacy, decoding and reading comprehension skills at age 6 (Hamilton 2013). These studies suggest that the home literacy environment a child experiences directly influences later language and literacy development independent of SES. Thus, SES and HLE are related entities, but provide distinct contributions to reading acquisition. HLE's unique influence on emergent literacy provides an opportunity for targeted intervention in order to buffer less modifiable factors such as genetic predisposition for reading difficulty, as seen in DD.

Studies investigating the nature of the relationship between HLE and reading success have further observed HLE to be related to oral language, phonological sensitivity, and word decoding ability in preschoolers (Burgess et al. 2002). Storybook exposure, a term used to describe informal literacy activities and defined by factors such as child exposure to literacy material, parent-child literary interactions, number of books in the home, and age when reading to the child began, predicts oral language and phonological awareness in preschool children after controlling for SES (Hamilton 2013; Sénéchal and LeFevre 2002). Direct instruction of words, letters, and reading skills predicts concurrent letter knowledge and early word reading (Hamilton 2013; Sénéchal and LeFevre 2002). HLE experienced before schooling begins also has a lasting impact, predicting reading skills into second grade through effects on vocabulary knowledge and printed word recognition in earlier years (Storch and Whitehurst 2001).

The effects of HLE in children with genetic predisposition for reading disability, however, are less clear. Correlations between storybook reading and early cognitive skills were found to be stronger in pre-readers with a family history of dyslexia compared to typical developing children (Torppa et al. 2007). Recent work has also identified positive correlations between storybook exposure and phoneme awareness in both FHD+ and FHDchildren, yet this correlation was observed at age five in FHD+ children compared to age four in FHD- (Hamilton 2013). Similarly, the developmental shift from letter knowledge to phoneme awareness occurs 2 years later in children with a family history of DD (Pennington and Lefly 2001). Notably, HLE was found to be a stronger predictor of reading readiness than family risk in children genetically predisposed to develop dyslexia. In fact, family risk did not account for any variance in reading readiness once HLE and a measure of overall child health were taken into account (Dilnot et al. 2016). While HLE seems to significantly impact reading development in children with and without a predisposition for dyslexia, the neural underpinnings are not well understood. Examining the neurobiological influence of HLE in individuals with predisposition for dyslexia will lead to a better understanding of the complex genetic and environmental influences that contribute to literacy acquisition. Understanding how this unique modifiable environmental characteristic may influence neurobiological circuits involved in emergent literacy may also help explain why some children who are genetically at-risk for DD never develop this learning disorder later in life. 
Evidence from the literature on SES provides a precedent for examining associations between the environment and reading networks in the brain. Neuroimaging data has revealed structural brain differences in gray matter volume, gyrification, cortical thickness, and surface area associated with SES (Hair et al. 2013; Hanson et al. 2013; Jednoróg et al. 2012; Lawson et al. 2013; Noble et al. 2015; Noble et al. 2012). Moreover, two fMRI studies have examined a relationship between SES and brain activation during language tasks. In schoolaged children with below-average phonological skill, Noble et al. observed that SES determined the predictive ability of phonological awareness on fusiform gyrus activation during a pseudoword task (Noble et al. 2006). In preschool children, Raizada and colleagues identified a correlation between SES and degree of left-hemispheric specialization in the inferior frontal gyrus during a rhyming task (Raizada et al. 2008). These differences in brain structure and function in relation to SES strongly suggest an environmental influence on brain development early in life. Furthermore, one study has examined the relationship between HLE and brain activity in preschool-aged children and identified a positive correlation between brain activity and parent-child reading in the left parietal-temporaloccipital association cortex during a story-listening task (Hutton et al. 2015). The authors concluded that strong HLE is associated with greater brain activation in areas involved in mental imagery and narrative comprehension. This study provided the first evidence that parent-child reading positively affects the neural circuits underlying oral language skills. This knowledge is especially important considering the public health implications of identifying neuroanatomical pathways underlying a potentially modifiable risk factor such as HLE, however the influence of genetic predisposition for dyslexia on these relationships remains unknown.

In this study, we investigate the relationship between HLE and neural correlates of phonological processing using functional neuroimaging techniques in beginning readers with and without a family history of DD. Phonological awareness, or the ability to manipulate the sounds of spoken language, has been identified as a key factor in the development of early reading (Adams 1990; Lundberg et al. 1980; Wagner et al. 1997; Chistopher J Lonigan et al. 2000; Wagner et al. 1994). In addition, differences in patterns and intensity of brain activation during reading-related tasks have been observed to correspond to performance on behavioral tests of phonological processing ability (Hoff 2003; Raschle et al. 2012; B. A. Shaywitz et al. 2002; Temple et al. 2001; Turkeltaub et al. 2003; Simos et al. 2002) and phonological awareness has been shown to mediate the relationship between HLE and acquisition of print-to-sound knowledge (Frijters et al. 2000). We controlled for parent education, an aspect of SES thought to be most closely tied to cognitive experiences in the home, to isolate the effects of HLE (Hoff-Ginsberg and Tardif 1995). In addition, our analysis is restricted to beginning readers to identify the effect of the home environment before literacy exposure in school.

We hypothesize that children with a more enriched HLE demonstrate increased activation in reading-associated brain regions due to the documented positive relationships between HLE and behavioral measures of reading. Importantly, the relationship between HLE and brain activation should be evident when controlling for parent education, as HLE has been shown to mediate effects of SES on language and literacy development. Furthermore, we predict differences in correlation of HLE and brain activation between FHD- and FHD+ children, 
as the relationship between HLE and brain activation may interact with genetic predisposition for $\mathrm{DD}$.

\section{Materials and Methods}

\section{Participants}

Fifty native English-speaking children with (FHD+, n=29, mean age $=67.46$ months, $\mathrm{SD}=$ 5.19 months) and without (FHD-, $\mathrm{n}=21$, mean age $=64.95$ months, $\mathrm{SD}=3.18$ months) a family history of DD were studied. All children were enrolled in a longitudinal dyslexia study. Family history status is determined by the presence of at least one first-degree family member with a clinical diagnosis of DD. To be enrolled in the FHD- group, no first-degree family members had a clinical diagnosis of DD or a family history of reading difficulties. Children with a family history of self-reported reading difficulties, but no clinical diagnosis of DD, were excluded from the study. No study participants had a comorbid diagnosis of ADHD. Participating families are invited each year for 2 visits, including 1 behavioral standardized testing session and 1 neuroimaging session. Imaging and behavioral data assessed in the first year, prior to formal reading instruction, were included in the present study. No participant had any history of neurological or psychological disorder, head injury, poor vision, or poor hearing. During an initial screening by telephone or email, parents were asked about their child's reading status. Only non-reading children entering kindergarten in the same year were invited to take part in the study. To further ensure status as beginning readers, the Word Identification subtest of the Woodcock Reading Mastery Test was administered to all children (Woodcock 1987). All children included in the present study recognized no more than 10 single words. All children were tested between May and November before entering kindergarten. This study was approved by institutional review. Verbal assent and informed consent were obtained from each child and guardian, respectively.

\section{Behavioral Testing}

Participants were characterized with a battery of standardized cognitive assessments examining language and prereading skills, such as expressive and receptive vocabulary [Clinical evaluation of language functions (CELF); (Semel et al. 1980)], phonological processing [Comprehensive test of phonological processing (CTOPP); (Wagner et al. 1999)], rapid automatized naming [RAN; (Wolf and Denckla 2005)], and verb agreement tense [VATT; (Van Der Lely 2000)]. Both verbal and non-verbal IQ were also assessed using the Kaufman Brief Intelligence Test (KBIT).

\section{Home Literacy Environment}

Parents were asked to complete a questionnaire at the time of fMRI imaging to assess HLE (Table 1). The questionnaire consisted of 16 multiple-choice or fill-in questions that assessed various family variables such as parent literacy practices, exposure to storybooks, direct instruction of reading and child interest in literacy. The questions chosen to be included in the composite HLE score were based on previous studies identifying the importance of both informal and formal aspects of HLE on reading development (Sénéchal et al. 1998). Storybook exposure served as the measure for informal literacy activities and was evaluated 
by questions pertaining to number of children's books in the home, age of child when first read to, frequency of reading to the child and frequency of the child looking at books. Formal activities were measured by direct instruction of writing and the alphabet. These aspects of HLE contribute to distinct aspects of language and early literacy (Sénéchal 2006; Sénéchal and LeFevre 2002). In contrast, observing family literacy behaviors does not influence acquisition of early reading skills, so questions characterizing this feature of HLE were not included in the composite score (Burgess et al. 2002; Hamilton 2013). Questions concerning child interest in reading were also excluded due to evidence from the literature that this entity should be considered distinct from aspects of HLE such as shared reading and direct instruction (Frijters et al. 2000; Scarborough and Dobrich 1994). Similarly, a question about writing related to the frequency of family members teaching a child how to write was excluded due to the conceptual distinction between reading and writing skills. Parent responses to each question were scored on a Likert scale and then converted to the percent of maximum possible score [POMP; (P. Cohen et al. 1999)]. The 6 items that made up the final HLE measure were subjected to a Confirmatory Factor Analysis (CFA) model using Maximum Likelihood estimation. Results indicated that the unidimensional structure was fully supported by the data with the overall Chi-square test, albeit being an index of 'exact fit' being non-significant $\left[\chi^{2}(9)=7,985, p=.536\right]$. Furthermore, the unstandardized residuals (i.e., RMSEA) were less than $1 \%$ and several fit indices pointed to minimal discrepancies between observed and hypothesized variance-covariance matrices (CFI $=1.00, T L I=1.00$, $\mathrm{IFI}=1.00, \mathrm{GFI}=.948$ ). Before creating a composite HLE variable, however, it was essential to also establish the internal consistency reliability of the measure. Following limitations of commonly used estimates of reliability such as Cronbach's alpha (which assumes tau equivalence, Sijtsma 2009) and composite reliability (which does not optimally weight items, Geldhof et al. 2014), maximal reliability $\mathrm{H}$ was estimated (Bentler 2007), which represents true scale reliability using an optimally weighted composite. Results indicated the maximal reliability was equivalent to 0.833 , which is excellent for congeneric measures.

The final six items that made up our composite HLE score included measures of storybook exposure and direct reading instruction (see Table 1 for more details). These aspects of HLE independently contribute to distinct aspects of language and early literacy (Sénéchal 2006; Sénéchal and LeFevre 2002). Children whose parents responded to fewer than 8 out of 9 questions were excluded from further analysis.

\section{Socioeconomic Status - Parent Education}

A second questionnaire was used to characterize each subject's socioeconomic background. These questions were taken from the MacArthur Research Network sociodemographic questionnaire (http://www.macses.ucsf.edu/Default.htm). One feature of SES, parent education, was used as a covariate in this analysis to control for SES. Family income was not included because of the high proportion of missing responses. The reported level of education for each parent was assigned a value from 1 to 7 ( 1 = Less than High School, $2=$ Some High School, 3 = Completed High School, 4 = Associate's Degree or some college, 5 $=$ Completed college, 6 = Master's or some graduate school, $7=$ Doctorate or equivalent). The values for each parent were then averaged, or an individual value was taken for single parents, to create a measure of parent education with a maximum score of 7 . 


\section{Correlations of HLE with Parent Education and Behavioral Scores}

Correlations of HLE with parent education (PE), phonological awareness (PA), and behavioral measures of prereading and language skills were performed to better understand how HLE relates to these factors. PA was quantified by averaging each child's standard scores on the CTOPP Ellison and CTOPP Blending subtests. Spearman's rank was used to assess the correlation of HLE with PE and PA, as the data were non-normally distributed. Pearson correlations were computed to assess the relationship between HLE and behavioral measures of language and prereading skills.

\section{Data Acquisition Paradigm}

The neuroimaging session included structural imaging acquisitions plus a total of $3 \mathrm{fMRI}$ tasks. These tasks investigated phonological processing, rapid auditory processing and executive function. Only one of the fMRI tasks, phonological processing, was included in the present study and is further described here. The fMRI task used in this study is identical to that described by Raschle et al. (2012). Each child performed one experimental task (firstsound matching; FSM) and one control task (voice-matching; VM). The design of these two tasks was identical and the order of the runs was pseudorandomized across children. During the experimental run, children performed a phonological processing task that involved listening to two sequentially presented common-object words spoken in a female or male voice (Figure 1). Pictures of the objects were presented on the screen simultaneously. Children were asked to indicate with a button-press whether the two words started with the same first sound (e.g., bed and belt, "yes") or not (e.g., bird and ant, "no"). This first-sound matching (FSM) task was contrasted with a rest condition. During the rest condition, children were asked to look at a fixation cross for the duration of the block. The control or voice-matching (VM) task also involved listening to two common-object words spoken in a female or male voice. Mirroring the experimental task, pictures that illustrated the spoken words were presented on the screen simultaneously. Participants were asked to indicate by button-press whether or not the sex of the voice matched for the two words presented. This task was also contrasted with a rest condition. Based on experience gained from a preliminary pilot study, the two tasks were presented in separate runs to avoid confusion in young prereading children (Raschle et al. 2012).

A behavioral interleaved gradient imaging design allowed for the presentation of the auditory stimuli without scanner background noise interference (Gaab et al. 2007a, 2007b, 2008; Hall et al. 1999). All images were acquired on a SIEMENS 3T Trio MR scanner using a T2*-weighted echo planar imaging (EPI) sequence with the following specifications: 32 slices; TR/TA/TE $=6000 / 2000 / 38 \mathrm{msec} ; \mathrm{FOV}=256 \times 256 \mathrm{~mm}$; matrix size $=64 \times 64$; flip angle $90^{\circ}$; slice thickness $=4 \mathrm{~mm}$; in plane resolution $3 \times 3 \mathrm{~mm}^{2}$. For each run (experiment and control), a total of seven blocks of the experimental/control condition and seven blocks of the rest condition were acquired for a total imaging time of 5.6 minutes. Each block contained four trials and each trial lasted 6 seconds. The order of trials within a block was randomized. For each run (experiment and control), the match and non-match conditions were well balanced. Each child underwent extensive preparation and training in the mock MR scanner area before the actual neuroimaging session (Raschle et al. 2012). Instructions for each task were presented in separate short videos, which were shown in the mock MR 
scanner area and repeated before actual scanning. Children achieving less than $60 \%$ accuracy on FSM or VM tasks during the scan were not included in the present analysis.

\section{Pre-processing}

Functional MRI data were pre-processed using SPM8 software (http:// www.fil.ion.ucl.ac.uk/spm/software/spm8/, Welcome Trust, London, United Kingdom), including realignment, co-registration, normalization, and spatial smoothing with an 8-mm full width at half maximum (FWHM) Gaussian kernel. Because of the age of participants, a rigorous procedure for artifact detection was used for each child (Art-Imaging Toolbox: https://www.nitrc.org/projects/artifact_detect/). Additionally, preprocessed images were used to create an explicit mask excluding potential artifactual time points. Movement regressors were identified using a movement threshold of $3 \mathrm{~mm}$ and a rotation threshold of $0.05 \mathrm{~mm}$. Children were only included in the present study when more than $80 \%$ of the images were artifact-free, which resulted in the 50 children characterized above. For each child, the general linear model (GLM) implemented in SPM8 was used to analyze the fMRI data in a block design. Contrast images for experimental > control condition (first-sound matching $(\mathrm{FSM})>$ voice matching $(\mathrm{VM}))$ were generated.

\section{Statistical Analysis}

Two-tailed, two-sample t-tests were used to examine differences in HLE and SES between FHD+ and FHD- children, respectively. A power analysis was conducted to ensure that neither Type-I nor Type-II errors were committed. Results indicated that power levels were $79.1 \%$ for a two-tailed test at an alpha level of 5\% using a large effect size based on Cohen (1992), that is .80 of a standard deviation. The level of significance was set to $p<0.05$. The use of a large effect size further provided confidence that no finding could potentially reflect a Type-I error.

To examine the correlation between HLE and other measures such as parent education (PE), phonological awareness (PA), and language (CELF) measures, we used Spearman's rank correlation executed using the R system (version 3.1.0 64 bit; Ihaka and Gentleman 1996). Power for the correlation coefficient was estimated using Cohen's recommendations on what constitutes a small (0.10), medium (0.30) and large effect (0.50). Again, in order to have robust findings, a large effect was sought with power levels being $80 \%$ for a two-tailed test with 29 participants. Thus, with the current sample, power levels were equal to $96.5 \%$ for identifying significant bivariate correlations that were equal to or greater than 0.50 . The present sample size of 50 participants provided power equal to $80 \%$ to identify significant correlation coefficients that ranged between medium-to-large sizes (i.e., $r=.40$ ).

Power for the Confirmatory Factor Analysis model was tested via a Monte Carlo simulation. Thus, a one-factor six-item model was simulated with $\mathrm{n}=50$ cases and standardized factor loadings equal to 0.50 and residual variances equal to .75 . Using 1,000 simulated samples, our results indicated that power levels ranged between 83.6 and $85.9 \%$ to identify significant items with those factor loadings. Coverage (amount of confidence intervals containing the true value) ranged between 93.4 and 93.9\%. Evaluation of power using the Chi-square test indicated that correct rejections were observed at $6.4 \%$ of the simulated samples compared 
to the tested 5\% level of significance, which again was very close to the true estimate. These simulated findings generally agree with our previous simulation study in which 50 participants were adequate for both $80 \%$ power levels in confirmatory factor analysis, but also the stability of estimated parameters (Sideridis et al. 2014).

To study the relationship between HLE, behavioral, and imaging measures, a multiple regression second-level analysis in SPM8 was performed. We specifically examined the correlation between HLE and functional activation during the phonological processing task (FSM > VM contrast) while controlling for PE, PA and family history of dyslexia. PA was added as a covariate in order to examine the unique effects of HLE independent of PA skills. In addition, to examine the relationship between HLE and genetic predisposition, FHD+ and FHD- groups were analyzed separately for correlation between HLE and brain activity when controlling for PE and PA in SPM8. Finally, we examined which brain regions showed group differences in brain-behavioral correlation between FHD- and FHD+ children using a multiple regression module in SPM8. First, the FSM>VM contrast images from both groups, as the dependent variable, were entered into second-level analysis with the HLE composite scores and binary familial risk status ( 0 for FHD- group, 1 for FHD+ group) as covariates and $\mathrm{PE}$ and PA as nuisance variables in the multiple regression module (Eilam-Stock et al. 2014). In addition, the interaction between HLE and familial status was included in the regression model. Post-hoc analyses were conducted to check the direction of the group differences. The statistical significance threshold for whole-brain analyses was set as $p<$ 0.001 uncorrected and a cluster size $\mathrm{k}>10$. An uncorrected threshold was employed since several studies have reported lower signal to noise ratios in young children, as well as differences in the shape and amplitude of the hemodynamic response function (Jacobs et al. 2008; Thomason et al. 2005; Wilke et al. 2003). All reported coordinates are in MNI space. For this modeling the magnitude of the correlation coefficients was evaluated using Cohen's conventions about the effect size of the $r$ statistic (1992).

\section{Results}

\section{Demographics and Behavioral Results}

Demographics and behavioral results are listed in Table 2. FHD+ children scored significantly lower than FHD- children in standardized assessments of rapid automatized naming [RAN objects $\left(\mathrm{t}_{(48)}=3.653 ; p=0.0007\right)$; and colors $\left(\mathrm{t}_{(48)}=3.181 ; p=0.0023\right)$ ], core language skills [CELF core language $\left(\mathrm{t}_{(48)}=2.307 ; p=0.021\right)$ ], receptive language skills [CELF receptive language $\left(\mathrm{t}_{(48)}=2.174 ; p=0.033\right)$ ], expressive language skills [CELF expressive language $\left(\mathrm{t}_{(48)}=2.455 ; p=0.014\right)$ ], and language structure [CELF language structure $\left.\left(\mathrm{t}_{48}\right)=2.726 ; p=0.007\right)$ ]; Verb Agreement and Tense Test [VATT repetition $\left.\left(\mathrm{t}_{(48)}=3.896 ; p=0.0003\right)\right]$. Parents of our participants came from well-educated backgrounds, with an average parent education score of 5.19 (Bachelor's Degree) and a range of 3 (HS/GED) to 7 (Doctorate or equivalent). There was no statistical difference between composite HLE scores of FHD+ $($ mean $=34.15 \pm 8.86)$ and FHD- $($ mean=36.88 $\pm 9.08)$ children in our sample $\left(\mathrm{t}_{(48)}=1.06, p=0.296\right)$. No significant differences in parent education, socioeconomic characteristics, or home literacy measures were identified 
between FHD+ and FHD- children (see Tables 3 and 4 for full lists of HLE and socioeconomic characteristics).

\section{Correlations of HLE with Parent Education and Behavioral Scores}

Parent education did not correlate with HLE using Spearman's rank correlation $(r=-0.05, p$ $=0.73)$. Phonological awareness and HLE also failed to show a significant correlation ( $r=$ $0.23, p=0.12$ ). The absence of a correlation between phonological awareness and HLE allows for more precise isolation of the relationship between HLE and brain activity during a phonological processing task, especially when controlling for PA. Lastly, a Pearson's product-moment correlation coefficient was computed to assess the relationship between HLE and expressive and receptive language. Positive correlations were identified between HLE and CELF core language $(r=0.28, p<0.05)$, CELF expressive language $(r=0.32, p<$ $0.05)$, and CELF language structure $(r=0.31, p<0.05)$ scores.

\section{Correlations of HLE with fMRI activation during a phonological processing task}

To identify the relationship between HLE and brain function, a multiple regression analysis was employed to examine the correlation between HLE score and fMRI activation during a phonological processing task (FSM > VM contrast). A positive correlation was identified between HLE scores and activation for the FSM > VM contrast when controlling for parent education, family history status and phonological awareness (see Figure 2) in several cortical brain regions including left inferior frontal gyrus ( $r=.55)$, left fusiform gyrus $(r=.40)$, right fusiform gyrus $(r=.50)$ and anterior right superior temporal gyrus $(r=.58 ; \mathrm{n}=50, p<0.001$ uncorrected, $\mathrm{k}>$ 10; see Table 5).

Separate multiple regression analyses were also performed for both FHD- and FHD+ children to examine the relationship between HLE and brain activation in children with and without a genetic predisposition for dyslexia (see Figure 3). For FHD- children, three clusters including the left inferior frontal gyrus ( $r=.78)$, right fusiform gyrus ( $r=.77)$, and anterior right superior temporal gyrus $(r=0.63)$ showed significant correlation between HLE and brain activity during a phonological processing task $(\mathrm{n}=21 ; p<0.001$ uncorrected, $\mathrm{k}>$ $10)$. For FHD+ children, only the right precentral gyrus ( $r=.61)$ showed a significant correlation between HLE and brain activity ( $\mathrm{n}=29 ; p<0.001$ uncorrected, $\mathrm{k}>10)$. Group differences between FHD- and FHD+ children (FHD- > FHD+) revealed significantly stronger correlations between HLE and brain activation in the left middle frontal gyrus $\left(r_{F H D=}=0.70 ; r_{F H D+}=0.39\right)$, left inferior frontal gyrus $\left(r_{F H D-}=0.59 ; r_{F H D+}=0.41\right)$ and right fusiform gyrus $\left(r_{F H D}=0.75 ; r_{F H D+}=0.28\right)$ when comparing FHD- to FHD+ children. The opposite contrast (FHD+ > FHD-) yielded one region that demonstrated a stronger correlation between HLE and activation in the right precentral gyrus $\left(r_{F H D}=0.27\right.$; $r_{F H D+}=0.38, p<0.001$ uncorrected, $\mathrm{k}>10$; see Table 6).

\section{Discussion}

To understand the relationship between home language/literacy environment and the neural substrates of reading, this study utilized whole-brain fMRI to examine correlations between HLE and brain activation during a phonological processing task in children beginning to 
read. Our data revealed positive correlations between brain activation and HLE in several cortical brain regions, including the left inferior frontal gyrus (IFG), bilateral fusiform gyri (FG), and right anterior superior temporal gyrus (STG). The observed relationship between HLE and functional activation cannot be explained by parent education, as we controlled for this factor in our analyses. In addition, our data showed stronger correlations of HLE with brain activation in the left IFG, left middle frontal gyrus (MFG) and right FG in FHDcompared to FHD+ children. One region, the right precentral gyrus (PG), demonstrated significantly stronger correlation in FHD+ children compared to FHD- children. This is the first neuroimaging study to identify brain regions that may be especially sensitive to differences in language/literacy exposure in beginning readers with DD after controlling for parent education and the child's current level of phonological awareness. It also provides new evidence for a differential relationship between HLE and brain activation in children with and without a genetic predisposition for dyslexia.

The brain regions correlated with HLE in our study are all observed within characteristic reading networks including occipito-temporal and inferior frontal regions (Schlaggar and McCandliss 2007). A richer HLE corresponded to increased activation in these regions during a phonological processing task, in agreement with literature that demonstrates correlations of increasing brain activation with reading proficiency (Hoff 2003; Raschle et al. 2012; Turkeltaub et al. 2003). The brain regions identified in this study were also consistent with those identified in several functional neuroimaging studies investigating the relationship of SES with early reading skills (Noble et al. 2006; Raizada et al. 2008). In addition, increased activation in these regions has been observed after reading intervention in children and adults with reading difficulties (Barquero et al. 2014; Hoeft et al. 2007; Richards and Berninger 2008; B. A. Shaywitz et al. 2004; Temple et al. 2003), which indicates the importance of these regions in learning to read and in reading remediation.

A recent study by Hutton et al. observed HLE to be correlated with activation in the left parietal-temporal-occipital association cortex during a story-listening task (Hutton et al. 2015). Notably, this is the first study to examine the relationship between HLE and the neuroanatomical circuits of emergent literacy. The present study, however, differs from that of Hutton and colleagues in experimental task and the associated reading network components, as Hutton et al. employed a story-listening task recruiting semantic processing skills, whereas the present study assessed brain activation during a task of phonological processing. Semantic processing supports comprehension of the meaning of words, while phonological processing is important in the decoding of words (Horowitz-Kraus et al. 2013; Pugh et al. 2013; Chistopher J Lonigan et al. 2000; Adams 1990). Separate neuroanatomical networks of phonological and semantic processing have also been described (Binder et al. 2009; Drakesmith et al. 2015; Raschle et al. 2012; Schlaggar and McCandliss 2007; Pugh et al. 2001). It is therefore not surprising that activation of unique brain regions was observed during these distinctive reading-related tasks. In addition, the HLE composite created in the present study included aspects of both storybook exposure and direct instruction of the alphabet, whereas a reading subscale from StimQ-P that did not include instruction was used by Hutton and colleagues (Hutton et al. 2015). Storybook reading and direct instruction of reading are considered distinct informal and formal literacy activities, respectively (Sénéchal 2006; Sénéchal and LeFevre 2002). The results of the present study and those of Hutton et 
al. may indicate that different brain regions are more sensitive to individual aspects of HLE. Importantly, our study provides new information on the relationship between HLE and brain activation in children genetically predisposed to develop dyslexia. Nevertheless, our findings provide additional evidence that HLE is positively associated with brain activation supporting skills crucial for the development of reading.

A positive correlation between HLE and activation in the left IFG during phonological processing is in line with previous findings that showed a correlation between increasing left-right asymmetry and SES in the IFG of 5-year-olds during a rhyming task (Raizada et al. 2008). The left IFG is an integral region within the reading network, specifically for phonological awareness and phonological naming (Turkeltaub et al. 2003). Beginning readers demonstrate increased activation of the left IFG (Turkeltaub et al. 2003). The importance of engagement of this region is demonstrated in studies of children with dyslexia who often exhibit hypoactivation in left inferior frontal regions (Booth et al. 2007; Brambati et al. 2006; Cao et al. 2006; Schulz et al. 2008). Our data suggest that this important readingrelated region is related to HLE prior to reading onset.

Our results also revealed a positive correlation between HLE and activation in bilateral FG. The left FG, often referred to as the Visual Word Form Area (VWFA), is sensitive to written words and develops in parallel with reading acquisition as children learn to quickly recognize visually presented words (McCandliss et al. 2003; Wimmer et al. 2010). The right FG, symmetrical to the left FG, is activated by visual words relative to fixation and is suggested to contribute to residual reading abilities (L. Cohen et al. 2003). Our study, however, implemented a task involving phonological analysis of spoken words. Activation of the VWFA in response to auditory stimuli is thought to represent top-down recruitment of orthographic representations of spoken words (Dehaene and Cohen 2011; Dehaene et al. 2010; Desroches et al. 2010; Yoncheva et al. 2010). Importantly, children with reading difficulties demonstrate reduced activation in the VWFA during an auditory rhyme-decision task compared to typical children (Desroches et al. 2010). Successful reading progression therefore relies on the development of connections between phonology and orthography. Noble et al. identified an SES-dependent relationship between phonological skill and engagement of the left FG in school-aged children (Noble et al. 2006). Our study, however, examined children without formal reading instruction. The observed correlation within bilateral and not just the left FG can be interpreted as evidence of right hemisphere involvement in early reading development. This result can also be understood in the context of previous fMRI studies which have shown that left lateralization of language networks develops slowly throughout childhood and does not peak until around 20 years of age (Brown et al. 2005; Holland et al. 2001; Szaflarski et al. 2006). Furthermore, our results have shown positive correlation between HLE and activation in the right anterior STG. This region has been associated with auditory sentence comprehension (Humphries et al. 2001) and vowel sound extraction (Obleser et al. 2006). Therefore, HLE may boost auditory comprehension ability in children during early reading development.

In this study, we identified a set of brain regions that showed differential correlations between HLE and brain activation in FHD- compared to FHD+ children. Notably, we observed a correlation between HLE and activity in the left IFG, left MFG and right FG in 
FHD- when compared to FHD+ children. This finding cannot be accounted for by group differences in HLE. The left MFG, along with IFG, forms part of the anterior reading network. FHD+ compared to FHD- children seem to show an altered relationship between HLE and components of the typical reading network during the early-reading years, as indicated by decreased correlations between HLE and activation in brain regions involved in typical reading development. This is in line with previous research that reported a correlation of storybook exposure with phoneme awareness in 5 year old FHD+ children that was one year delayed compared to typical children (Hamilton 2013). The authors further suggest that HLE may only contribute to phonological awareness in FHD+ children after formal reading instruction has begun in school (Hamilton 2013). In addition, Torppa et al. propose that in prereading children with a familial risk for DD, phonological processing may be the largest contributor to delayed letter learning, while in typical children several factors including memory skills, rapid symbol processing/retrieval and HLE may overshadow phonological sensitivity in letter knowledge development (Torppa et al. 2006). As our study only examined the functional relationship between HLE and phonological awareness in children before formal reading instruction, future longitudinal work should assess how early HLE affects later reading skills.

When comparing the relationship between HLE and brain activation in FHD+ and FHDchildren, one brain region in the right PG displayed increased correlation in FHD+ compared to FHD- children. Several studies have identified recruitment of compensatory networks within the right hemisphere that demonstrate hyperactivation in children with DD compared to controls (Hoeft et al. 2011; Hoeft et al. 2007; S. E. Shaywitz et al. 1998). Increased activation in these regions (e.g. precentral gryus and inferior frontal gyrus) further predicts reading improvement in children with DD several years later (Hoeft et al., 2011). It is therefore possible that in some children with $\mathrm{DD}$, unique brain regions involved in compensation for dysfunctional reading networks may be most sensitive to HLE or may develop as a result of experience-dependent plasticity. In this way, HLE may serve as a protective factor in reading development in children with FHD+, especially those who will develop typical reading skills. This is especially interesting since only about 50\% of FHD+ children will develop DD and it is unclear whether high HLE scores will mediate future reading development in FHD+ children. Future studies should examine how HLE contributes to the development of hyperactivation in compensatory reading networks and its role as a protective factor for FHD+ in general.

In this study, we observed no correlation between composite HLE score and parent education. The degree of correlation between HLE and SES has been shown to depend on the component of HLE examined. Storybook reading most strongly correlates with SES, while aspects such as direct language instruction do not (Hamilton 2013). The use of a composite score including both shared reading and direct instruction may have dampened the relationship between HLE and SES in this study. A more likely contributor, however, is the overall high SES background of our children. Nonetheless, our finding ensures that parent education does not confound the association between HLE and brain activation. Similarly, no correlation was observed between HLE and phonological awareness, allowing us to isolate the effects of HLE regardless of phonological skill level. We did identify a positive correlation between HLE and CELF core language, expressive language, and 
language structure scores. These results demonstrate a link between higher HLE and enhanced early language skills in children, consistent with previous behavioral studies (Burgess et al. 2002; De Jong and Leseman 2001; Levy et al. 2006; Niklas and Schneider 2013; Schmitt et al. 2011; Sénéchal and LeFevre 2002; Sénéchal et al. 1998). Importantly, the HLE construct employed in this study was developed after careful review of the literature, however, there is currently no uniformly accepted measure of HLE and issues related to content validity are still debatable. Several methodological concerns have been identified in previous studies, which address the inconsistent component factors of HLE, the various methods of collecting information on HLE and whether to employ and narrow or broad definition of HLE (for discussion, please see: Christopher J. Lonigan 1994; Schmitt et al. 2011). In the present study, our hybrid measure, which involved items from previous instruments, possessed excellent reliability and also factorial validity.

Several limitations of the present study must be taken into consideration. First, we obtained data on HLE for each subject through self-report provided by parents. Our comprehensive questionnaire allowed for a wide range of responses, but may have been subject to exaggeration due to the influence of social desirability (Stanovich and West 1989). We assume, however, that any tendency to inflate HLE characteristics would be consistent across children. Second, although we propose that the observed group differences are biological in nature (e.g. the FHD+ are unable to take full advantage of the provided HLE), an alternative explanation would be that some of these children have parents with a reading disability or at least lower reading scores and that therefore their HLE may not be as effective, especially in terms of quality of book reading. Although we did not observe significant differences in HLE between groups, we did not measure quality of shared book reading. However, a review by Scarborough and Dobrich revealed that the quality of shared reading does not provide any added benefit over the quantity on language or literacy development (Scarborough and Dobrich 1994). We therefore think that any effect, if present, is most likely minimal. Third, our results must be considered in light of the homogenous socioeconomic background of our study participants. Examination of demographic data reveals a substantial representation of high-SES families, identified by self-report on factors such as income, education, occupation, and perceived social standing. This characteristic of our study population may also explain why we did not observe a correlation between HLE score and parent education. Future work should aim to assess the effects of HLE in a sample with widely varying socioeconomic demographics in an effort to include children exposed to both extremes of HLE. Fourth, due to the nature of this study, the correlations observed do not imply a causal link between HLE and brain activation. Future studies should aim to operationalize HLE variables in order to draw causal conclusions. Finally, our fMRI results are reported with an uncorrected threshold. This implies a significant risk of Type I errors (Lieberman and Cunningham 2009; Nichols and Hayasaka 2003). In the present study, an uncorrected threshold was employed since several studies have reported lower signal to noise ratios in young children, as well as differences in the shape and amplitude of the hemodynamic response function, which potentially can lead to decreased weighted parameter estimates, a problem that is currently not accounted for in standardized analysis packages (Jacobs et al. 2008; Richter and Richter 2003; Thomason et al. 2005; Wilke et al. 2003). Our reported fMRI clusters all lie within the reading network and these areas were 
hypothesized to show a correlation with home literacy measures a priori. We therefore think that our results are valid, but that results need to be interpreted with caution.

Acknowledging these caveats, we conclude that early exposure to literacy materials, shared reading, and reading instruction in the home may interact with and/or contribute to underlying differences in the neural correlates of reading development, especially in children with genetic predisposition for DD compared to typically developing children. Cortical brain regions that demonstrate a relationship between HLE and brain activation include the left IFG, bilateral FG, and right STG. Genetic predisposition for dyslexia, however, may alter the relationship between HLE and brain activation during phonological processing, as certain brain regions show increased sensitivity to HLE only in FHD- children. Therefore, one could hypothesize that genetic contributions may either outweigh those of the environment at early stages of reading development or that there is a differential interactions between genetic contributions and environmental influences in children with a family history of dyslexia. However the impact of HLE on brain activation at later stages of reading development remains unclear. Our results also provide evidence for compensatory brain networks in FHD+ children that demonstrate increased sensitivity to HLE. To our knowledge, this is the first neuroimaging study to examine the relationship between literacy exposure in the home and the neural correlates of phonological processing, a key component of early reading skill. This work highlights the need to consider HLE characteristics in future studies investigating reading development in general, brain characteristics of dyslexia, as well as the roles of the environment in cognitive/language development in children. This knowledge will broaden our understanding of how the environment shapes language development in order to provide children the greatest opportunity for success in reading.

\section{Acknowledgments}

This research is supported by the National Institute of Child Health and Human Development under grant 1R01HD065762-05.

\section{References}

Adams, MJ. Beginning to read: Learning and thinking about print. Cambridge, MA: MIT Press; 1990.

Barquero LA, Davis N, Cutting LE. Neuroimaging of reading intervention: a systematic review and activation likelihood estimate meta-analysis. PloS one. 2014; 9(1):e83668. [PubMed: 24427278]

Bentler, PM. Covariance structure models for maximal reliability of unit-weighted composites. In: Lee, S., editor. Handbook of computing and statistics with applications: Vol. 1 Handbook of latent variable and related models. New York, NY: Elsevier; 2007. p. 1-19.

Binder JR, Desai RH, Graves WW, Conant LL. Where is the semantic system? A critical review and meta-analysis of 120 functional neuroimaging studies. Cerebral Cortex. 2009; 19(12):2767-2796. [PubMed: 19329570]

Bishop D. The interface between genetics and psychology: lessons from developmental dyslexia. Proceedings of the Royal Society of London B: Biological Sciences. 2015; 282(1806):20143139.

Booth JR, Bebko G, Burman DD, Bitan T. Children with reading disorder show modality independent brain abnormalities during semantic tasks. Neuropsychologia. 2007; 45(4):775-783. [PubMed: 17010394]

Brambati SM, Termine C, Ruffino M, Danna M, Lanzi G, Stella G, et al. Neuropsychological deficits and neural dysfunction in familial dyslexia. Brain research. 2006; 1113(1):174-185. [PubMed: 16934234] 
Brito NH, Noble KG. Socioeconomic status and structural brain development. Frontiers in neuroscience. 2014; 8

Brown TT, Lugar HM, Coalson RS, Miezin FM, Petersen SE, Schlaggar BL. Developmental changes in human cerebral functional organization for word generation. Cerebral Cortex. 2005; 15(3):275290. [PubMed: 15297366]

Burgess SR, Hecht SA, Lonigan CJ. Relations of the home literacy environment (HLE) to the development of reading-related abilities: A one-year longitudinal study. Reading Research Quarterly. 2002; 37(4):408-426.

Bus AG, Van Ijzendoorn MH, Pellegrini AD. Joint book reading makes for success in learning to read: A meta-analysis on intergenerational transmission of literacy. Review of educational research. 1995; 65(1):1-21.

Cao F, Bitan T, Chou TL, Burman DD, Booth JR. Deficient orthographic and phonological representations in children with dyslexia revealed by brain activation patterns. Journal of Child Psychology and Psychiatry. 2006; 47(10):1041-1050. [PubMed: 17073983]

Christopher ME, Hulslander J, Byrne B, Samuelsson S, Keenan JM, Pennington B, et al. Genetic and Environmental Etiologies of the Longitudinal Relations Between Prereading Skills and Reading. Child development. 2015; 86(2):342-361. [PubMed: 25263167]

Cohen J. A power primer. Psychological Bulletin. 1992; 112:155-159. [PubMed: 19565683]

Cohen L, Martinaud O, Lemer C, Lehericy S, Samson Y, Obadia M, et al. Visual word recognition in the left and right hemispheres: anatomical and functional correlates of peripheral alexias. Cerebral Cortex. 2003; 13(12):1313-1333. [PubMed: 14615297]

Cohen P, Cohen J, Aiken LS, West SG. The Problem of Units and the Circumstance for POMP. Multivariate Behavioral Research. 1999; 34(3):315-346.

Darki F, Peyrard-Janvid M, Matsson H, Kere J, Klingberg T. Three dyslexia susceptibility genes, DYX1C1, DCDC2, and KIAA0319, affect temporo-parietal white matter structure. Biological psychiatry. 2012; 72(8):671-676. [PubMed: 22683091]

De Jong PF, Leseman PP. Lasting effects of home literacy on reading achievement in school. Journal of School Psychology. 2001; 39(5):389-414.

DeFries JC, Alarcón M. Genetics of specific reading disability. Mental Retardation and Developmental Disabilities Research Reviews. 1996; 2(1):39-47.

Dehaene $\mathrm{S}$, Cohen $\mathrm{L}$. The unique role of the visual word form area in reading. Trends in cognitive sciences. 2011; 15(6):254-262. [PubMed: 21592844]

Dehaene S, Pegado F, Braga LW, Ventura P, Nunes Filho G, Jobert A, et al. How learning to read changes the cortical networks for vision and language. Science. 2010; 330(6009):1359-1364. [PubMed: 21071632]

Desroches AS, Cone NE, Bolger DJ, Bitan T, Burman DD, Booth JR. Children with reading difficulties show differences in brain regions associated with orthographic processing during spoken language processing. Brain research. 2010; 1356:73-84. [PubMed: 20691675]

Dilnot J, Hamilton L, Maughan B, Snowling MJ. Child and environmental risk factors predicting readiness for learning in children at high risk of dyslexia. Development and Psychopathology, FirstView. 2016:1-10.

Drakesmith M, El-Deredy W, Welbourne S. Differential Phonological and Semantic Modulation of Neurophysiological Responses to Visual Word Recognition. Neuropsychobiology. 2015; 72(1):4656. [PubMed: 26337735]

Ehri LC. Development of sight word reading: Phases and findings. 2005

Eilam-Stock T, Xu P, Cao M, Gu X, Van Dam NT, Anagnostou E, et al. Abnormal autonomic and associated brain activities during rest in autism spectrum disorder. Brain. 2014; 137(1):153-171. [PubMed: 24424916]

Frijters JC, Barron RW, Brunello M. Direct and mediated influences of home literacy and literacy interest on prereaders' oral vocabulary and early written language skill. Journal of Educational psychology. 2000; 92(3):466.

Gaab N, Gabrieli JD, Glover GH. Assessing the influence of scanner background noise on auditory processing. I. An fMRI study comparing three experimental designs with varying degrees of scanner noise. Human brain mapping. 2007a; 28(8):703-720. [PubMed: 17080440] 
Gaab N, Gabrieli JD, Glover GH. Assessing the influence of scanner background noise on auditory processing. II. An fMRI study comparing auditory processing in the absence and presence of recorded scanner noise using a sparse design. Human brain mapping. 2007b; 28(8):721-732. [PubMed: 17089376]

Gaab N, Gabrieli JD, Glover GH. Resting in peace or noise: Scanner background noise suppresses default-mode network. Human brain mapping. 2008; 29(7):858-867. [PubMed: 18454447]

Galaburda AM, LoTurco J, Ramus F, Fitch RH, Rosen GD. From genes to behavior in developmental dyslexia. Nature neuroscience. 2006; 9(10):1213-1217. [PubMed: 17001339]

Galaburda AM, Sherman GF, Rosen GD. Developmental Dyslexia: Four Consecutive Patients with Cortical Anomahes. Reading. 1985; 6:1.8.

Geldhof GJ, Preacher KJ, Zyphur MJ. Reliability estimation in a multilevel confirmatory factor analysis framework. Psychological Methods. 2014; 19:72-91. [PubMed: 23646988]

Grigorenko EL. Genetic bases of developmental dyslexia: A capsule review of heritability estimates. 2004

Hackman DA, Farah MJ. Socioeconomic status and the developing brain. Trends in cognitive sciences. 2009; 13(2):65-73. [PubMed: 19135405]

Hair, N.; Hanson, J.; Pollak, S.; Wolfe, B. Socioeconomic differences and academic achievement: Insights from the developing brain; Washington, DC. APPAM Annual Fall Research Conference; 2013.

Hall DA, Haggard MP, Akeroyd MA, Palmer AR, Summerfield AQ, Elliott MR, et al. "Sparse" temporal sampling in auditory fMRI. Human brain mapping. 1999; 7(3):213-223. [PubMed: 10194620]

Hamilton L. The role of the home literacy environment in the early literacy development of children at family-risk of dyslexia. 2013

Hanson JL, Hair N, Shen DG, Shi F, Gilmore JH, Wolfe BL, et al. Family poverty affects the rate of human infant brain growth. 2013

Hoeft F, McCandliss BD, Black JM, Gantman A, Zakerani N, Hulme C, et al. Neural systems predicting long-term outcome in dyslexia. Proceedings of the National Academy of Sciences. $2011 ; 108(1): 361-366$.

Hoeft F, Meyler A, Hernandez A, Juel C, Taylor-Hill H, Martindale JL, et al. Functional and morphometric brain dissociation between dyslexia and reading ability. Proceedings of the National Academy of Sciences. 2007; 104(10):4234-4239.

Hoff E. The specificity of environmental influence: Socioeconomic status affects early vocabulary development via maternal speech. Child development. 2003; 74(5):1368-1378. [PubMed: 14552403]

Hoff-Ginsberg E, Tardif T. Socioeconomic status and parenting. 1995

Holland SK, Plante E, Byars AW, Strawsburg RH, Schmithorst VJ, Ball WS. Normal fMRI brain activation patterns in children performing a verb generation task. Neuroimage. 2001; 14(4):837843. [PubMed: 11554802]

Horowitz-Kraus T, Vannest JJ, Holland SK. Overlapping neural circuitry for narrative comprehension and proficient reading in children and adolescents. Neuropsychologia. 2013; 51(13):2651-2662. [PubMed: 24029377]

Humphries C, Willard K, Buchsbaum B, Hickok G. Role of anterior temporal cortex in auditory sentence comprehension: an fMRI study. Neuroreport. 2001; 12(8):1749-1752. [PubMed: 11409752]

Hutton JS, Horowitz-Kraus T, Mendelsohn AL, DeWitt T, Holland SK. Home Reading Environment and Brain Activation in Preschool Children Listening to Stories. Pediatrics. 2015; 136(3):466-478. [PubMed: 26260716]

Ihaka R, Gentleman R. R: a language for data analysis and graphics. Journal of computational and graphical statistics. 1996; 5(3):299-314.

Jacobs J, Hawco C, Kobayashi E, Boor R, LeVan P, Stephani U, et al. Variability of the hemodynamic response as a function of age and frequency of epileptic discharge in children with epilepsy. Neuroimage. 2008; 40(2):601-614. [PubMed: 18221891] 
Jednoróg K, Altarelli I, Monzalvo K, Fluss J, Dubois J, Billard C, et al. The influence of socioeconomic status on children's brain structure. PloS one. 2012; 7(8):e42486. [PubMed: 22880000]

Kere J. The molecular genetics and neurobiology of developmental dyslexia as model of a complex phenotype. Biochemical and biophysical research communications. 2014; 452(2):236-243. [PubMed: 25078623]

Lawson GM, Duda JT, Avants BB, Wu J, Farah MJ. Associations between children's socioeconomic status and prefrontal cortical thickness. Developmental science. 2013; 16(5):641-652. [PubMed: 24033570]

Levy BA, Gong Z, Hessels S, Evans MA, Jared D. Understanding print: Early reading development and the contributions of home literacy experiences. Journal of Experimental Child Psychology. 2006; 93(1):63-93. [PubMed: 16140318]

Lieberman MD, Cunningham WA. Type I and Type II error concerns in fMRI research: rebalancing the scale. Soc Cogn Affect Neurosci. 2009; 4(4):423-428. [PubMed: 20035017]

Lonigan CJ. Reading to Preschoolers Exposed: Is the Emperor Really Naked? Developmental review. 1994; 14(3):303-323.

Lonigan CJ, Burgess SR, Anthony JL. Development of emergent literacy and early reading skills in preschool children: evidence from a latent-variable longitudinal study. Developmental psychology. 2000; 36(5):596. [PubMed: 10976600]

Lundberg I, Olofsson $\AA$, Wall S. Reading and spelling skills in the first school years predicted from phonemic awareness skills in kindergarten. Scandinavian Journal of Psychology. 1980; 21(1):159173.

Lyon GR, Shaywitz SE, Shaywitz BA. A definition of dyslexia. Annals of dyslexia. 2003; 53(1):1-14.

McCandliss BD, Cohen L, Dehaene S. The visual word form area: expertise for reading in the fusiform gyrus. Trends in cognitive sciences. 2003; 7(7):293-299. [PubMed: 12860187]

Nichols T, Hayasaka S. Controlling the familywise error rate in functional neuroimaging: a comparative review. Stat Methods Med Res. 2003; 12(5):419-446. [PubMed: 14599004]

Niklas F, Schneider W. Home literacy environment and the beginning of reading and spelling. Contemporary Educational Psychology. 2013; 38(1):40-50.

Noble KG, Houston SM, Brito NH, Bartsch H, Kan E, Kuperman JM, et al. Family income, parental education and brain structure in children and adolescents. Nature neuroscience. 2015; 18(5):773778. [PubMed: 25821911]

Noble KG, Houston SM, Kan E, Sowell ER. Neural correlates of socioeconomic status in the developing human brain. Developmental science. 2012; 15(4):516-527. [PubMed: 22709401]

Noble KG, Wolmetz ME, Ochs LG, Farah MJ, McCandliss BD. Brain-behavior relationships in reading acquisition are modulated by socioeconomic factors. Developmental science. 2006; 9(6): 642-654. [PubMed: 17059461]

O'Brien BA, Wolf M, Lovett MW. A taxometric investigation of developmental dyslexia subtypes. Dyslexia. 2012; 18(1):16-39. [PubMed: 22228709]

Obleser J, Boecker H, Drzezga A, Haslinger B, Hennenlotter A, Roettinger M, et al. Vowel sound extraction in anterior superior temporal cortex. Human brain mapping. 2006; 27(7):562-571. [PubMed: 16281283]

Ozernov-Palchik O, Yu X, Wang Y, Gaab N. Lessons to be learned: How a comprehensive neurobiological framework of atypical reading development can inform educational practice. Current Opinion in Behavioral Sciences. In Press.

Payne AC, Whitehurst GJ, Angell AL. The role of home literacy environment in the development of language ability in preschool children from low-income families. Early Childhood Research Quarterly. 1994; 9(3):427-440.

Pennington BF, Lefly DL. Early reading development in children at family risk for dyslexia. Child development. 2001:816-833. [PubMed: 11405584]

Peterson RL, Pennington BF. Developmental Dyslexia. Annual review of clinical psychology. 2015; 11:283-307. 
Pugh KR, Landi N, Preston JL, Mencl WE, Austin AC, Sibley D, et al. The relationship between phonological and auditory processing and brain organization in beginning readers. Brain and language. 2013; 125(2):173-183. [PubMed: 22572517]

Pugh KR, Mencl WE, Jenner AR, Katz L, Frost SJ, Lee JR, et al. Neurobiological studies of reading and reading disability. Journal of communication disorders. 2001; 34(6):479-492. [PubMed: 11725860]

Raizada RD, Kishiyama MM. Effects of socioeconomic status on brain development, and how cognitive neuroscience may contribute to levelling the playing field. Frontiers in Human Neuroscience. 2010; 4(3)

Raizada RD, Richards TL, Meltzoff A, Kuhl PK. Socioeconomic status predicts hemispheric specialisation of the left inferior frontal gyrus in young children. Neuroimage. 2008; 40(3):13921401. [PubMed: 18308588]

Raschle NM, Zuk J, Gaab N. Functional characteristics of developmental dyslexia in left-hemispheric posterior brain regions predate reading onset. Proceedings of the National Academy of Sciences. 2012; 109(6):2156-2161.

Richards TL, Berninger VW. Abnormal fMRI connectivity in children with dyslexia during a phoneme task: Before but not after treatment. Journal of Neurolinguistics. 2008; 21(4):294-304. [PubMed: 19079567]

Richter W, Richter M. The shape of the fMRI BOLD response in children and adults changes systematically with age. Neuroimage. 2003; 20(2):1122-1131. [PubMed: 14568481]

Rodriguez ET, Tamis-LeMonda CS. Trajectories of the home learning environment across the first 5 years: Associations with children's vocabulary and literacy skills at prekindergarten. Child development. 2011; 82(4):1058-1075. [PubMed: 21679179]

Scarborough HS, Dobrich W. On the efficacy of reading to preschoolers. Developmental review. 1994; 14(3):245-302.

Scarborough HS, Dobrich W, Hager M. Preschool literacy experience and later reading achievement. Journal of Learning Disabilities. 1991; 24(8):508-511. [PubMed: 1940609]

Schlaggar BL, McCandliss BD. Development of neural systems for reading. Annu. Rev. Neurosci. 2007; 30:475-503. [PubMed: 17600524]

Schmitt SA, Simpson AM, Friend M. A longitudinal assessment of the home literacy environment and early language. Infant and Child Development. 2011; 20(6):409-431.

Schulz E, Maurer U, van der Mark S, Bucher K, Brem S, Martin E, et al. Impaired semantic processing during sentence reading in children with dyslexia: combined fMRI and ERP evidence. Neuroimage. 2008; 41(1):153-168. [PubMed: 18378166]

Semel, EM.; Wiig, EH.; Sabers, D. CELF: Clinical evaluation of language functions. CE Merrill; 1980.

Sénéchal M. Testing the home literacy model: Parent involvement in kindergarten is differentially related to grade 4 reading comprehension, fluency, spelling, and reading for pleasure. Scientific studies of reading. 2006; 10(1):59-87.

Sénéchal M, LeFevre JA. Parental involvement in the development of children's reading skill: A fiveyear longitudinal study. Child development. 2002; 73(2):445-460. [PubMed: 11949902]

Sénéchal M, Lefevre JA, Thomas EM, Daley KE. Differential effects of home literacy experiences on the development of oral and written language. Reading Research Quarterly. 1998; 33(1):96-116.

Shaywitz BA, Shaywitz SE, Blachman BA, Pugh KR, Fulbright RK, Skudlarski P, et al. Development of left occipitotemporal systems for skilled reading in children after a phonologically-based intervention. Biological psychiatry. 2004; 55(9):926-933. [PubMed: 15110736]

Shaywitz BA, Shaywitz SE, Pugh KR, Mencl WE, Fulbright RK, Skudlarski P, et al. Disruption of posterior brain systems for reading in children with developmental dyslexia. Biological psychiatry. 2002; 52(2):101-110. [PubMed: 12114001]

Shaywitz SE, Shaywitz BA, Pugh KR, Fulbright RK, Constable RT, Mencl WE, et al. Functional disruption in the organization of the brain for reading in dyslexia. Proceedings of the National Academy of Sciences. 1998; 95(5):2636-2641.

Sideridis GD, Simos P, Papanicolaou A, Fletcher J. On the use of SEM for evaluating functional connectivity in the brain: Sample size considerations. Educational and Psychological Measurement. 2014; 74:733-758. [PubMed: 25435589] 
Siegel LS. Perspectives on dyslexia. Paediatrics \& child health. 2006; 11(9):581. [PubMed: 19030329]

Sijtsma K. On the use, the misuse, and the very limited usefulness of Cronbach's alpha.

Psychometrika. 2009; 74:107-120. [PubMed: 20037639]

Simos PG, Fletcher JM, Foorman BR, Francis DJ, Castillo EM, Davis RN, et al. Brain activation profiles during the early stages of reading acquisition. Journal of Child Neurology. 2002; 17(3): 159-163. [PubMed: 12026228]

Smith SS, Dixon RG. Literacy concepts of low-and middle-class four-year-olds entering preschool. The Journal of Educational Research. 1995; 88(4):243-253.

Stanovich KE, West RF. Exposure to print and orthographic processing. Reading Research Quarterly. 1989:402-433.

Storch SA, Whitehurst GJ. The Role of family and home in the literacy development of children from low-income backgrounds. New directions for child and adolescent development. 2001; 2001(92): 53-72.

Swanson M, Wolff J, Elison J, Gu H, Hazlett H, Botteron K, et al. Splenium development and early spoken language in human infants. Developmental science. 2015

Szaflarski JP, Holland SK, Schmithorst VJ, Byars AW. fMRI study of language lateralization in children and adults. Human brain mapping. 2006; 27(3):202-212. [PubMed: 16035047]

Temple E, Deutsch GK, Poldrack RA, Miller SL, Tallal P, Merzenich MM, et al. Neural deficits in children with dyslexia ameliorated by behavioral remediation: evidence from functional MRI. Proceedings of the National Academy of Sciences. 2003; 100(5):2860-2865.

Temple E, Poldrack RA, Salidis J, Deutsch GK, Tallal P, Merzenich MM, et al. Disrupted neural responses to phonological and orthographic processing in dyslexic children: an fMRI study. Neuroreport. 2001; 12(2):299-307. [PubMed: 11209939]

Thomason ME, Burrows BE, Gabrieli JD, Glover GH. Breath holding reveals differences in fMRI BOLD signal in children and adults. Neuroimage. 2005; 25(3):824-837. [PubMed: 15808983]

Torppa M, Poikkeus A-M, Laakso M-L, Eklund K, Lyytinen H. Predicting delayed letter knowledge development and its relation to grade 1 reading achievement among children with and without familial risk for dyslexia. Developmental psychology. 2006; 42(6):1128. [PubMed: 17087547]

Torppa M, Poikkeus A-M, Laakso M-L, Tolvanen A, Leskinen E, Leppanen PH, et al. Modeling the early paths of phonological awareness and factors supporting its development in children with and without familial risk of dyslexia. Scientific studies of reading. 2007; 11(2):73-103.

Turkeltaub PE, Gareau L, Flowers DL, Zeffiro TA, Eden GF. Development of neural mechanisms for reading. Nature neuroscience. 2003; 6(7):767-773. [PubMed: 12754516]

Van Der Lely, H. Available from the author at the Centre for Developmental Language Disorders and Cognitive Neuroscience. London, UK: University College London; 2000. Verb agreement and tense test (VATT).

Wagner RK, Torgesen JK, Rashotte CA. Development of reading-related phonological processing abilities: New evidence of bidirectional causality from a latent variable longitudinal study. Developmental psychology. 1994; 30(1):73.

Wagner RK, Torgesen JK, Rashotte CA. CTOPP: Comprehensive test of phonological processing. Proed. 1999

Wagner RK, Torgesen JK, Rashotte CA, Hecht SA, Barker TA, Burgess SR, et al. Changing relations between phonological processing abilities and word-level reading as children develop from beginning to skilled readers: a 5-year longitudinal study. Developmental psychology. 1997; 33(3):468. [PubMed: 9149925]

Whitehurst GJ, Lonigan CJ. Child development and emergent literacy. Child development. 1998; 69(3):848-872. [PubMed: 9680688]

Wilke M, Holland SK, Myseros JS, Schmithorst VJ, Ball WS Jr. Functional magnetic resonance imaging in pediatrics. Neuropediatrics. 2003; 34(5):225-233. [PubMed: 14598227]

Wimmer H, Schurz M, Sturm D, Richlan F, Klackl J, Kronbichler M, et al. A dual-route perspective on poor reading in a regular orthography: an fMRI study. Cortex. 2010; 46(10):1284-1298. [PubMed: 20650450]

Wolf, M.; Denckla, MB. Rapid automatized naming and rapid alternating stimulus tests (RAN/RAS). Austin, TX: Pro-Ed; 2005. 
Woodcock, RW. Woodcock reading mastery tests, revised. MN: American Guidance Service Circle Pines; 1987.

World Health Organization. The ICD-10 classification of mental and behavioural disorders: clinical descriptions and diagnostic guidelines. Geneva: World Health Organization; 1992.

Yoncheva YN, Zevin JD, Maurer U, McCandliss BD. Auditory selective attention to speech modulates activity in the visual word form area. Cerebral Cortex. 2010; 20(3):622-632. [PubMed: 19571269] 


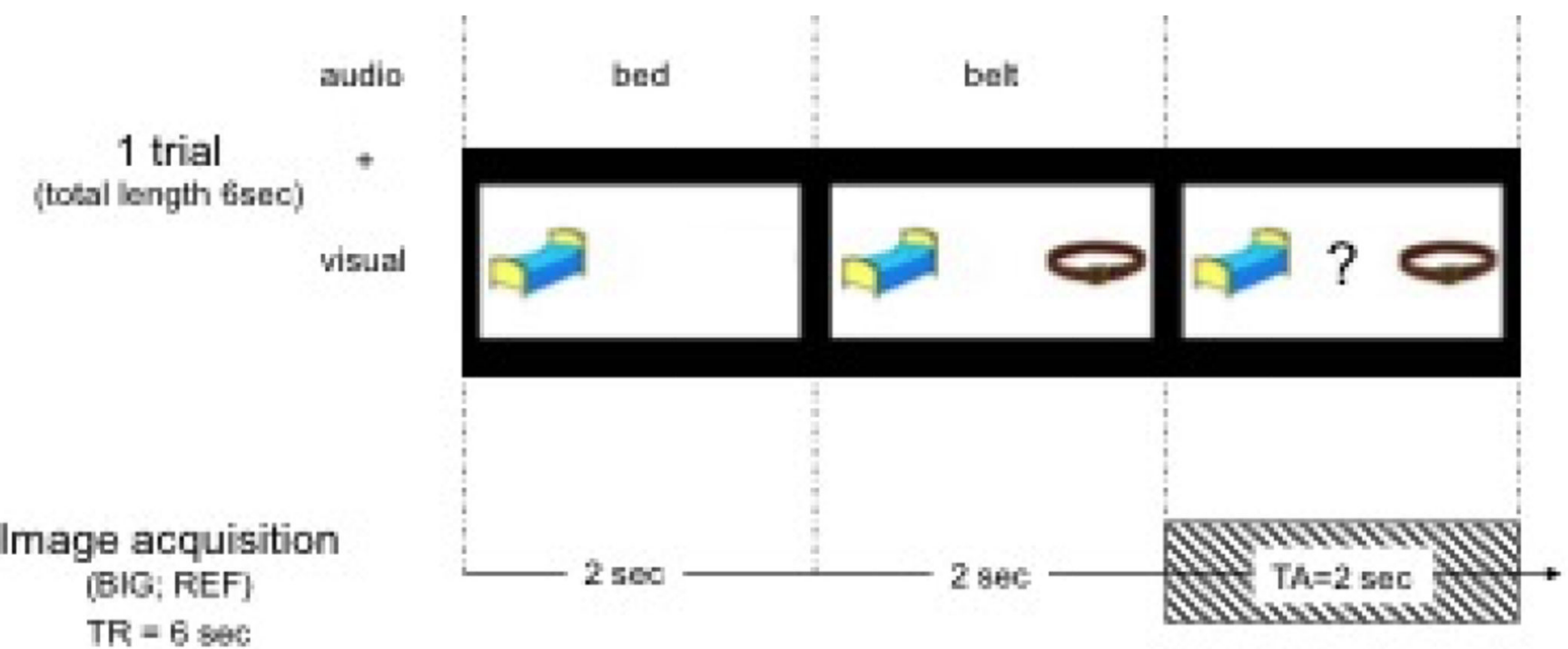

Fig. 1.

FMRI task design 


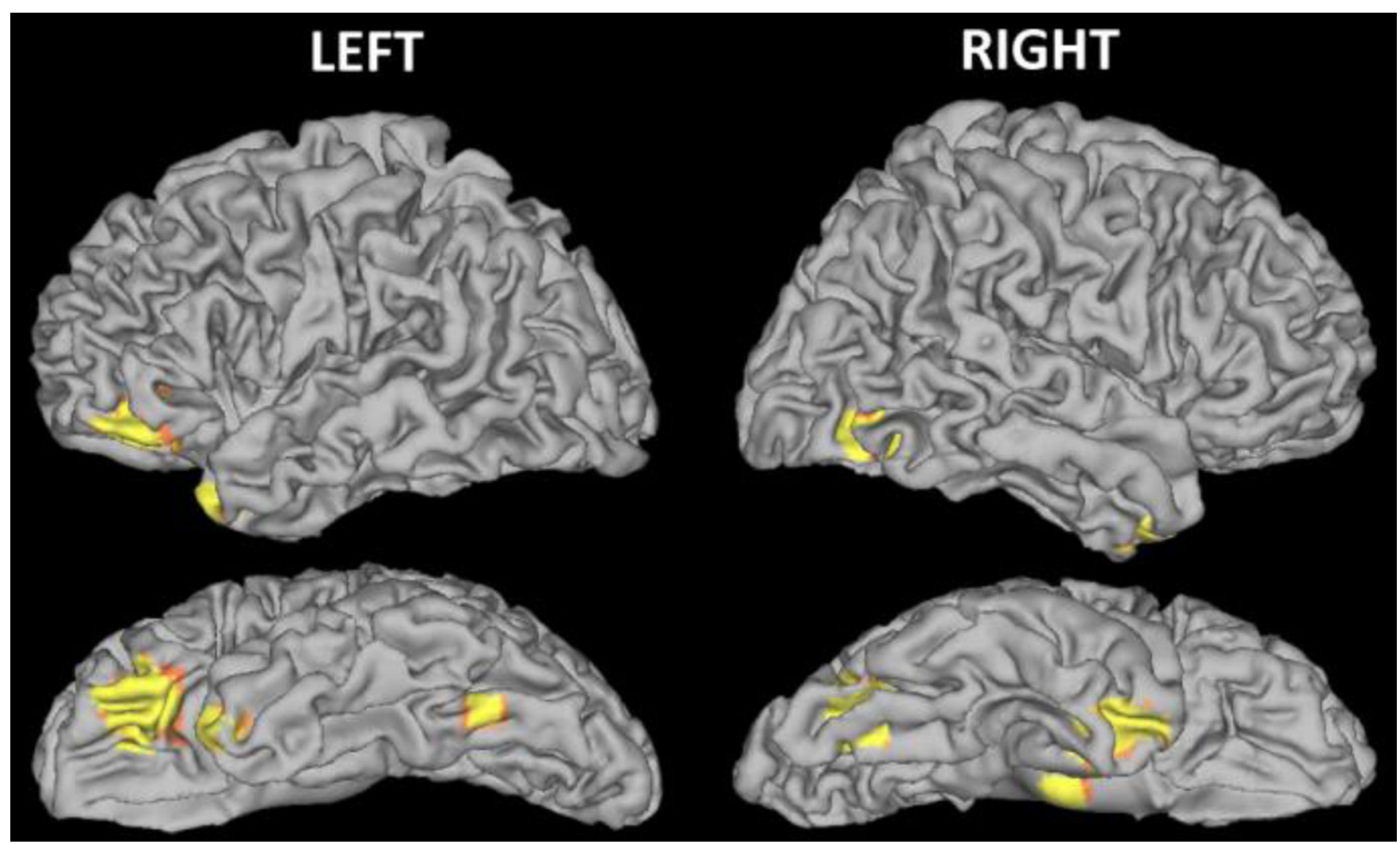

Fig. 2.

Statistical parametric maps showing correlation between brain activity and HLE during a phonological processing (FSM $>\mathrm{VM}$ ) task when FHD- and FHD+ children were pooled together $(p<0.001$ uncorrected, $\mathrm{k}=10)$ 

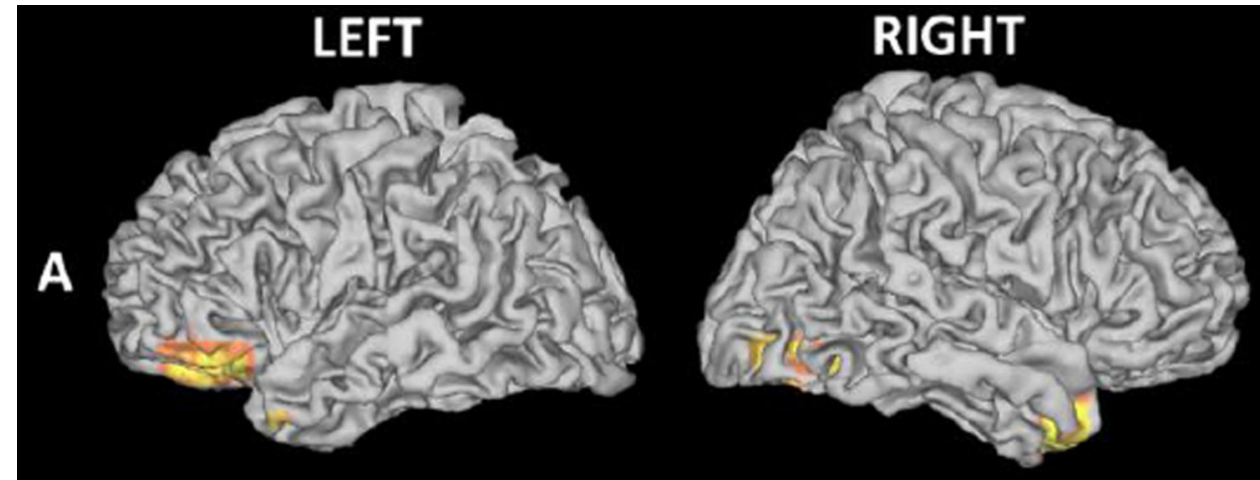

B
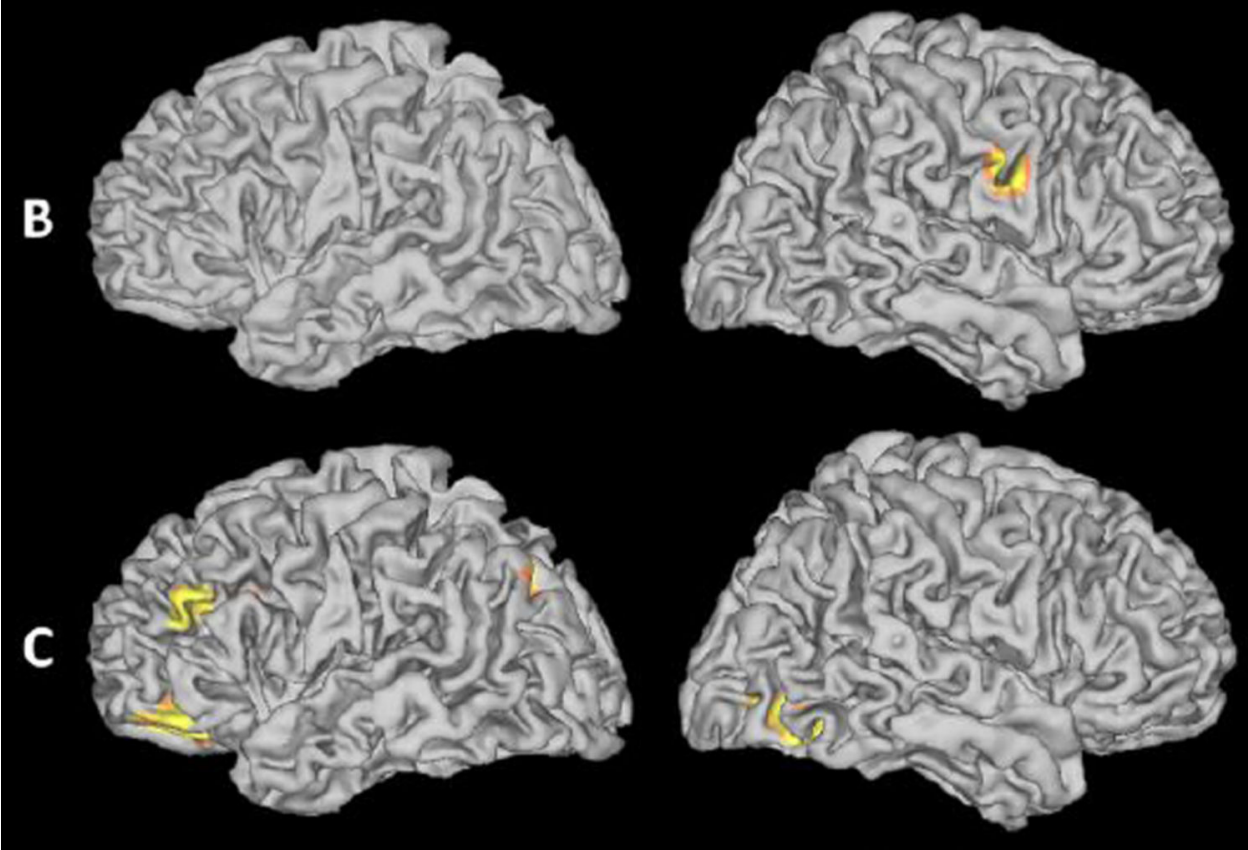

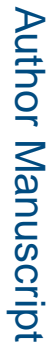
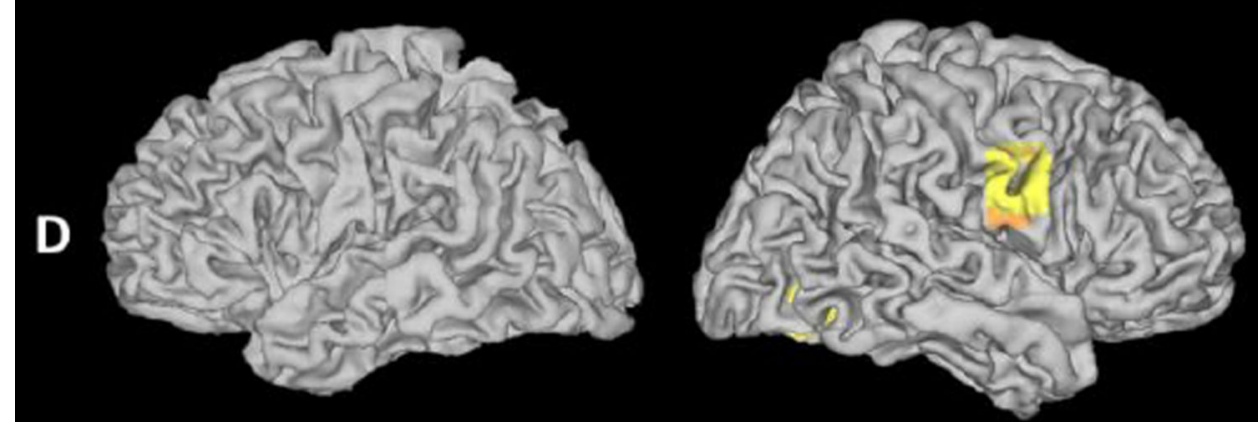

Fig. 3.

Statistical parametric maps showing correlation between brain activity and HLE during a phonological processing (FSM $>\mathrm{VM}$ ) task in (A) FHD- and (B) FHD+, group differences as (C) FHD- $>$ FHD+ and (D) FHD $-<$ FHD $+(p<0.001$ uncorrected, $\mathrm{k}=10)$ 
Table 1

Home literacy questions used to calculate composite HLE scores

\section{HLE Questions}

Total number of children's book in the home

Age (in months) of child when first read to

Amount of time at home (in hours) that someone reads to the child each week

How often do family members read books, magazines or newspapers with the child? (family members and/or tutors)

How often do family members teach the child the alphabet? (times/week)

How often does the child look at books at home by themselves? (times/week) 


\section{Table 2}

\section{Participant Demographics}

\begin{tabular}{|c|c|c|c|}
\hline & $\begin{array}{l}\text { FHD+ } \\
(\text { mean } \pm \text { SD })\end{array}$ & $\begin{array}{l}\text { FHD- } \\
(\text { mean } \pm \text { SD })\end{array}$ & $\begin{array}{l}p \text { values two-tailed } \\
\text { FHD+ vs. FHD- }\end{array}$ \\
\hline $\mathrm{n}$ & 29 & 21 & \\
\hline Age (in months) & $67.46 \pm 5.19$ & $64.95 \pm 3.18$ & 0.557 \\
\hline \multicolumn{4}{|l|}{ Gender } \\
\hline Female & 12 & 10 & \\
\hline Male & 17 & 11 & \\
\hline Parent Education & $5.05 \pm 0.97$ & $5.38 \pm 1.01$ & 0.254 \\
\hline HLE score (composite) & $34.15 \pm 8.86$ & $36.88 \pm 9.08$ & 0.296 \\
\hline \multicolumn{4}{|l|}{ Behavioral Measures } \\
\hline \multicolumn{4}{|l|}{$\underline{\text { CTOPP }}$} \\
\hline Elision & $9.66 \pm 1.97$ & $10.81 \pm 2.25$ & 0.067 \\
\hline Blending & $10.66 \pm 1.86$ & $11.33 \pm 1.65$ & 0.181 \\
\hline Non-Word Repetition & $9.38 \pm 1.84$ & $9.90 \pm 1.81$ & 0.320 \\
\hline Phonetic Awareness & $10.16 \pm 1.59$ & $11.07 \pm 1.71$ & 0.061 \\
\hline \multicolumn{4}{|l|}{$\underline{\text { RAN }}$} \\
\hline Objects & $94.00 \pm 11.37$ & $105.65 \pm 10.78$ & $0.0007^{* * * *}$ \\
\hline Colors & $93.07 \pm 13.81$ & $105.52 \pm 13.44$ & $0.0023^{* *}$ \\
\hline \multicolumn{4}{|l|}{$\underline{\text { CELF }}$} \\
\hline Core Language & $107.34 \pm 12.38$ & $114.95 \pm 10.17$ & $0.021^{*}$ \\
\hline Receptive Language & $105.97 \pm 11.34$ & $112.90 \pm 10.82$ & $0.033^{*}$ \\
\hline Expressive Language & $106.21 \pm 13.71$ & $115.00 \pm 10.57$ & $0.014^{*}$ \\
\hline Language Structure & $106.55 \pm 12.24$ & $115.38 \pm 9.85$ & $0.007^{* *}$ \\
\hline Language Content & $103.00 \pm 10.35$ & $110.60 \pm 12.61$ & 0.129 \\
\hline \multicolumn{4}{|l|}{$\underline{\text { VATT }}$} \\
\hline Inflection & $26.93 \pm 5.59$ & $28.55 \pm 3.94$ & 0.415 \\
\hline Repetition & $36.13 \pm 3.68$ & $39.33 \pm 0.87$ & $0.005^{* *}$ \\
\hline \multicolumn{4}{|l|}{$\underline{\text { KBIT }}$} \\
\hline Verbal & $112.06 \pm 8.76$ & $117.10 \pm 7.62$ & 0.131 \\
\hline Non-verbal & $101.24 \pm 11.75$ & $104.52 \pm 10.10$ & 0.295 \\
\hline Word ID & $0.73 \pm 2.19$ & $0.5 \pm 1.10$ & 0.661 \\
\hline
\end{tabular}

Note: CELF: Clinical Evaluation of Language Fundamentals; CTOPP: Comprehensive Test of Phonological Processing; KBIT: Kaufman Brief Intelligence Test; RAN: Rapid Automatized Naming; VATT: Verb Agreement and Tense Test.

$*$

${ }^{*}<0.05$;

${ }^{* * *}<<0.01$

****

$p<0.001 ;$ two-tailed t test; Standard scores are reported. 
Table 3

Home literacy environment characteristics

\begin{tabular}{|c|c|c|c|}
\hline Environment & FHD+ $(\%)$ & FHD- (\%) & $\begin{array}{l}\text { P significant } \\
\text { 2-tailed }\end{array}$ \\
\hline $\begin{array}{l}\text { Total number of children's books in the home } \\
\text { No response } \\
0-50 \\
51-150 \\
151-300 \\
300+\end{array}$ & $\begin{array}{l}6.90 \\
10.35 \\
49.38 \\
17.24 \\
17.61\end{array}$ & $\begin{array}{l}4.76 \\
4.76 \\
47.61 \\
33.33 \\
9.52\end{array}$ & 0.42 \\
\hline $\begin{array}{l}\text { Age (in months) of child when first read to } \\
\text { No response } \\
\text { Prenatal } \\
0-6 \\
6.1-24 \\
24+\end{array}$ & $\begin{array}{l}6.90 \\
3.45 \\
79.30 \\
6.90 \\
3.45\end{array}$ & $\begin{array}{l}4.76 \\
0 \\
80.94 \\
14.28 \\
0\end{array}$ & 0.58 \\
\hline $\begin{array}{l}\text { Amount of time at home (in hours) that someone } \\
\text { reads to the child each week }\end{array}$ & $3.05 \pm 1.82$ & $3.95 \pm 2.36$ & $0.13^{\dagger}$ \\
\hline $\begin{array}{l}\text { How often do family members read books, } \\
\text { magazines or newspapers with the child? } \\
\text { No response } \\
\text { 1-2 Times a Week } \\
\text { 3-4 Times a Week } \\
\text { 5-6 Times a Week } \\
\text { Daily }\end{array}$ & $\begin{array}{l}0 \\
6.90 \\
10.34 \\
31.03 \\
51.72\end{array}$ & $\begin{array}{l}0 \\
4.76 \\
4.76 \\
14.28 \\
76.19\end{array}$ & 0.13 \\
\hline $\begin{array}{l}\text { How often do family members teach the child the } \\
\text { alphabet? } \\
\text { No response } \\
\text { 1-2 Times a Week } \\
\text { 3-4 Times a Week } \\
\text { 5-6 Times a Week } \\
\text { Daily }\end{array}$ & $\begin{array}{l}3.45 \\
31.01 \\
27.59 \\
17.24 \\
20.68\end{array}$ & $\begin{array}{l}0 \\
52.38 \\
23.80 \\
14.28 \\
9.52\end{array}$ & 0.96 \\
\hline $\begin{array}{l}\text { How often does the child look at books at home } \\
\text { by themselves? } \\
\text { No response } \\
\text { 1-2 Times a Week } \\
\text { 3-4 Times a Week } \\
\text { 5-6 Times a Week } \\
\text { Daily }\end{array}$ & $\begin{array}{l}0 \\
4.76 \\
19.05 \\
9.52 \\
66.67\end{array}$ & $\begin{array}{l}0 \\
13.79 \\
17.24 \\
17.24 \\
51.73\end{array}$ & 0.27 \\
\hline
\end{tabular}

Note: Right columns contain the percent of parents selecting each answer choice and P significant for Mann-Whitney Tests performed on the given ordinal variables;

Independent samples t-test;

* $p<0.05$. 
Table 4

Socioeconomic characteristics

\begin{tabular}{|c|c|c|c|}
\hline & FHD+ $(\%)$ & FHD- $(\%)$ & $P$ significant 2-tailed \\
\hline Highest Level of Education (Mom) & & & 0.37 \\
\hline No response & 3.45 & 0 & \\
\hline High School/GED & 17.24 & 4.76 & \\
\hline Associate's or Some College & 3.45 & 4.76 & \\
\hline Bachelor's Degree & 27.58 & 47.62 & \\
\hline Master's Degree & 41.38 & 23.8 & \\
\hline Doctorate or Equivalent & 6.9 & 19.05 & \\
\hline Highest Level of Education (Dad) & & & 0.17 \\
\hline No response & 3.45 & 0 & \\
\hline High School/GED & 24.13 & 19.05 & \\
\hline Associate's or Some College & 6.9 & 0 & \\
\hline Bachelor's Degree & 31.03 & 33.33 & \\
\hline Master's Degree & 27.59 & 28.57 & \\
\hline Doctorate or Equivalent & 6.9 & 19.05 & \\
\hline Current Activities/Responsibilities (Mom) & & & 0.51 \\
\hline No response & 10.34 & 4.76 & \\
\hline Looking for Work & 3.45 & 4.76 & \\
\hline Keeping House/Raising Children & 41.38 & 42.86 & \\
\hline Work Part Time & 20.69 & 14.29 & \\
\hline Work Full Time & 24.13 & 33.33 & \\
\hline Current Activities/Responsibilities (Dad) & & & 0.83 \\
\hline No response & 55.17 & 52.38 & \\
\hline Looking for Work & 6.9 & 0 & \\
\hline Keeping House/Raising Children & 0 & 0 & \\
\hline Work Part Time & 0 & 9.52 & \\
\hline Work Full Time & 37.93 & 38.1 & \\
\hline $\begin{array}{l}\text { Earnings, Before Taxes and Other Deductions, } \\
\text { During the Past } 12 \text { Months }\end{array}$ & & & 0.11 \\
\hline No response & 13.79 & 33.33 & \\
\hline Less than $\$ 11,999$ & 24.13 & 28.57 & \\
\hline$\$ 12,000-\$ 34,999$ & 3.45 & 4.76 & \\
\hline$\$ 35,000-\$ 49,999$ & 10.34 & 4.76 & \\
\hline$\$ 50,000-\$ 74,999$ & 24.14 & 19.05 & \\
\hline$\$ 75,000-\$ 99,999$ & 6.9 & 4.76 & \\
\hline$\$ 100,000+$ & 10.34 & 4.76 & \\
\hline Family Income in the Last 12 Months & & & 0.54 \\
\hline No response & 6.89 & 23.8 & \\
\hline Don’t know & 44.83 & 38.09 & \\
\hline Less than $\$ 11,999$ & 3.45 & 0 & \\
\hline$\$ 12,000-\$ 34,999$ & 0 & 0 & \\
\hline$\$ 35,000-\$ 49,999$ & 3.45 & 9.53 & \\
\hline$\$ 50,000-\$ 74,999$ & 0 & 14.29 & \\
\hline$\$ 75,000-\$ 99,999$ & 24.13 & 14.29 & \\
\hline$\$ 100,000+$ & 20.68 & 0 & \\
\hline
\end{tabular}

Note: Right columns contain the percent of parents selecting each answer choice and P significant for Mann-Whitney Tests performed on the given ordinal variables;

$\mathrm{p}<0.05$. 


\section{Table 5}

Cortical regions displaying significant correlation ( $\mathrm{p}<0.001$ uncorrected; $\mathrm{k}=10$ ) between HLE composite scores and brain activity during a phonological processing task (FSM $>$ VM contrast)

\begin{tabular}{lllll}
\hline Region & $\begin{array}{l}\text { MNI Coordinates } \\
(\mathbf{x}, \mathbf{y}, \mathbf{z})\end{array}$ & $\begin{array}{l}\text { Cluster } \\
\text { Size } \\
\text { (voxels) }\end{array}$ & Z score & $\begin{array}{l}\text { Correlation } \\
\text { Coefficient (r) } \\
\text { and E.S. Metric }\end{array}$ \\
\hline Fusiform gyrus (L) & $-36,-60,-20$ & 11 & 3.34 & $0.40^{*}$ (Medium to Large) \\
Fusiform gyrus (R) & $36,-70,-10$ & 49 & 3.92 & $0.50^{*}$ (Large) \\
Inferior frontal gyrus (L) & $-42,38,-12$ & 171 & 4.13 & $0.55^{*}$ (Large) \\
Superior temporal gyrus (R) & $32,4,-28$ & 178 & 4.40 & $0.58^{*}$ (Large) \\
\hline * & & & &
\end{tabular}

E.S.=Effect size metric. Conventions regarding correlation coefficients were as follows: .10 (Small), .30 (Medium), and .50 (Large) based on the work of Cohen (1992). 


\section{Table 6}

Cortical regions displaying significant correlation ( $\mathrm{p}<0.001$ uncorrected; $\mathrm{k}=10$ ) between HLE composite scores and brain activity during a phonological processing task (FSM $>$ VM contrast) in FHD- and FHD+ children

\begin{tabular}{|c|c|c|c|c|}
\hline Region & $\begin{array}{l}\text { MNI Coordinates } \\
(\mathbf{x}, \mathbf{y}, \mathbf{z})\end{array}$ & $\begin{array}{l}\text { Cluster Size } \\
\text { (voxels) }\end{array}$ & $Z$ score & $\begin{array}{l}\text { Correlation } \\
\text { Coefficient (r) } \\
\text { and E.S. Metric }\end{array}$ \\
\hline \multicolumn{5}{|l|}{ FHD- } \\
\hline Inferior frontal gyrus (L) & $-38,24,-12$ & 329 & 4.40 & $0.78^{*}$ (Large) \\
\hline Fusiform gyrus (R) & $30,-70,-10$ & 105 & 4.12 & $0.77^{*}$ (Large) \\
\hline Superior temporal gyrus (R) & $32,10,-28$ & 87 & 4.40 & $0.63 *$ (Large) \\
\hline \multicolumn{5}{|l|}{$\underline{\mathrm{FHD}+}$} \\
\hline Precentral gyrus (R) & $54-632$ & 10 & 3.33 & $0.61 *$ (Large) \\
\hline \multicolumn{5}{|l|}{$\underline{\text { FHD- }->\text { FHD }+}$} \\
\hline Inferior frontal gyrus (L) & $-42,34,-8$ & 68 & 3.56 & $\begin{array}{l}\text { FHD- }(r=0.59) \\
\text { FHD+( } r=0.41)\end{array}$ \\
\hline Middle frontal gyrus (L) & $-42,30,24$ & 22 & 3.63 & $\begin{array}{l}\text { FHD- }(r=0.70) \\
\text { FHD+( } r=0.39)\end{array}$ \\
\hline Fusiform gyrus (R) & $30,-68,-10$ & 50 & 3.56 & $\begin{array}{l}\text { FHD- }(r=0.75) \\
\text { FHD+( }(=0.28)\end{array}$ \\
\hline \multicolumn{5}{|l|}{$\underline{\text { FHD }+>\text { FHD- }}$} \\
\hline Precentral gyrus (R) & $58-430$ & 38 & 4.07 & $\begin{array}{l}\text { FHD- }(r=0.27) \\
\text { FHD }+(r=0.38)\end{array}$ \\
\hline
\end{tabular}

Note: $p<0.05$

E.S.=Effect size metric. Conventions regarding correlation coefficients were as follows: .10 (Small), .30 (Medium), and .50 (Large) based on the work of Cohen (1992). 